\title{
Chapter The Effect of Radiotherapy on the Human Reproductive System
}

\author{
Tom W Kelsey, Chia-Ho Hua, and W Hamish B Wallace
}

\section{Introduction}

Cancer in childhood is rare. The most recent SEER Cancer Statistics Review, released in April 2018 and covering 2011-2015, shows that for ages 0-14 the incidence of all cancer sites was 16.4 per 100,000 children, with mortality 2.1 per 100,000 . Five-year relative survival for the same age group was $83.8 \%$ for years 2008-2014 [1]. (Rates from the European Cancer Information System are similar but are currently available only to 2012.) As of 2015, 1 in 750 of the adult population of the United States was a long-term survivor of childhood cancer [1,2]. Cancer is more common after puberty, with incidence rising from 12.9 for ages 5-9 to 23.3 for ages 15-19 in the United States for years 2011-2015 [1], and many of these patients will be cured by combination treatment, with surgery, chemotherapy, and radiotherapy. Long-term survivors are nevertheless at risk of developing a number of late sequelae [3], including impaired fertility, adverse pregnancy outcomes, and health problems in offspring [4-6]. Loss of fertility is one of the most devastating consequences of radiotherapy for these young patients, who, having overcome their disease, have expectations of a normal reproductive life.

\section{Normal Ovarian Development and Follicular Depletion}

Current understanding of the human ovarian reserve is that the ovary establishes several hundred thousand nongrowing follicles (NGFs) by followed by a decline in the population by menopause, when approximately 800 remain at an average age of 50-51 [7]. With approximately 450 ovulatory monthly cycles in the normal human reproductive life span, this progressive decline in NGF numbers is attributed to follicle death by apoptosis. The Wallace-Kelsey model of human ovarian reserve from conception to menopause best fits the combined histological evidence that has been described $[8,9]$ and validated using external data [7] (Figure 3.1). This model allows us to estimate the number of NGFs present in the ovary at any given age, and it suggests that $81 \%$ of the variance in NGF populations is due to age alone. Further analysis demonstrates that $95 \%$ of the NGF population variation is due to age alone for ages up to 25 . The remaining $5 \%$ is due to factors other than age, e.g. smoking, body mass index (BMI), parity, and stress. We can speculate that as chronological age increases, factors other than age become more important in determining the rate at which NGFs are lost through apoptosis.

There is speculation that this widely held tenet of mammalian ovarian function may require revision. A report in 2004 suggested the presence of germ stem cells in the adult mouse ovary [10], with two subsequent reports by the same group suggesting the ability of bone marrow-derived cells to give rise to new immature oocytes [11, 12]. More recently, another group has identified the presence of proliferative and culturable female germline stem cells in newborn and adult mouse ovaries [13]. Strikingly, when these cells (transgenically labeled) were injected into a chemotherapytreated ovary, they became enclosed within follicles and offspring bearing the transgene were produced. These data provide a basis for reevaluating the regenerative capacity of the mammalian ovary and new approaches for overcoming fertility loss. While the emerging evidence thus appears to provide evidence in support of the existence of germ stem cells within the adult mammalian ovary, there is no robust evidence to date that these cells contribute to follicle formation leading to viable eggs [14]. There is evidence that significant NGF population regeneration can occur in extreme situations in the human ovary [15], but the Wallace-Kelsey model of ovarian follicle decline provides no 
Wallace-Kelsey model of NGF population with age in healthy women

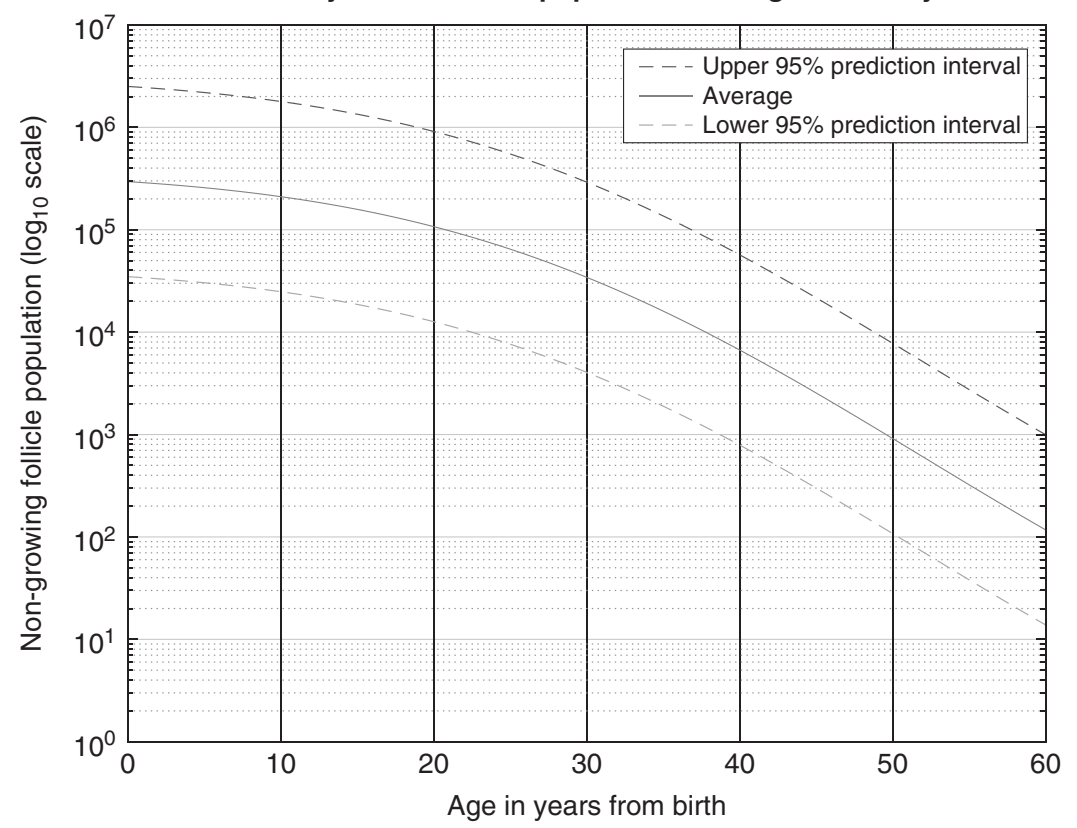

Figure 3.1 The Wallace-Kelsey model of NGF decline from birth to age 60. The average ovary contains 300,000 NGFs at birth, declining to 100,000 at age 20, with about 800 remaining at average age of menopause (50-51 years)

supporting evidence of neo-oogenesis in normal human physiological aging.

\section{Radiation and the Hypothalamic- Pituitary-Ovarian Axis}

The ovaries may be damaged following total body, abdominal, or pelvic irradiation [16], and the extent of the damage is related to the radiation dose, fractionation schedule, and age at the time of treatment [17-19]. The human oocyte is sensitive to radiation, with an estimated $\mathrm{LD}_{50}$ of less than 2 Gy [20]. This is the lethal dose to destroy $50 \%$ of NGFs present in the ovary. The number of NGFs present at the time of treatment, together with the dose received by the ovaries, will determine the "fertile window" and influence the age of premature ovarian insufficiency (POI). Longterm ovarian failure has been reported in $90 \%$ of patients after total body irradiation (TBI) (10.00$15.75 \mathrm{~Gy}$ ) and in $97 \%$ of females treated with total abdominal irradiation (20-30 Gy) during childhood [21-23]. Our understanding of the $\mathrm{LD}_{50}$ of the human oocyte has made it possible to estimate the age at which POI may occur (Figure 3.2). Furthermore, we have estimated the sterilizing dose following any given dose of radiotherapy at any given age, based upon the Wallace-Kelsey model for NGF decline (Figure 3.3) [24, 25]. This will help clinicians provide accurate information when counseling women about fertility following treatment for childhood cancer. Gonadotropin deficiency following high-dose cranial irradiation (more than $24 \mathrm{~Gy}$ in the treatment of brain tumors) manifests as delayed puberty or absent menses and can be treated by hormone replacement therapy. Interestingly, early puberty is often reported in females with cranial radiation doses of less than 24 Gy [26]. However, we have shown a subtle decline in hypothalamic- pituitary-ovarian function following low-dose cranial radiotherapy (18-24 Gy). This is characterized by decreased luteinizing hormone (LH) secretion throughout the cycle, an attenuated LH surge, and short luteal phases [27], which may compromise reproductive function. Cranial radiotherapy is also associated with increased risk of oligomenorrhea, reduced estradiol, and increased prolactin in survivors $[28,29]$. Recent data confirm lower fertility in childhood cancer survivors treated with either hypothalamic/pituitary irradiation more than 22 Gy or ovarian/uterine irradiation more than 5 Gy $[30,31]$. Nowadays, the most commonly used fertility preservation measure is 


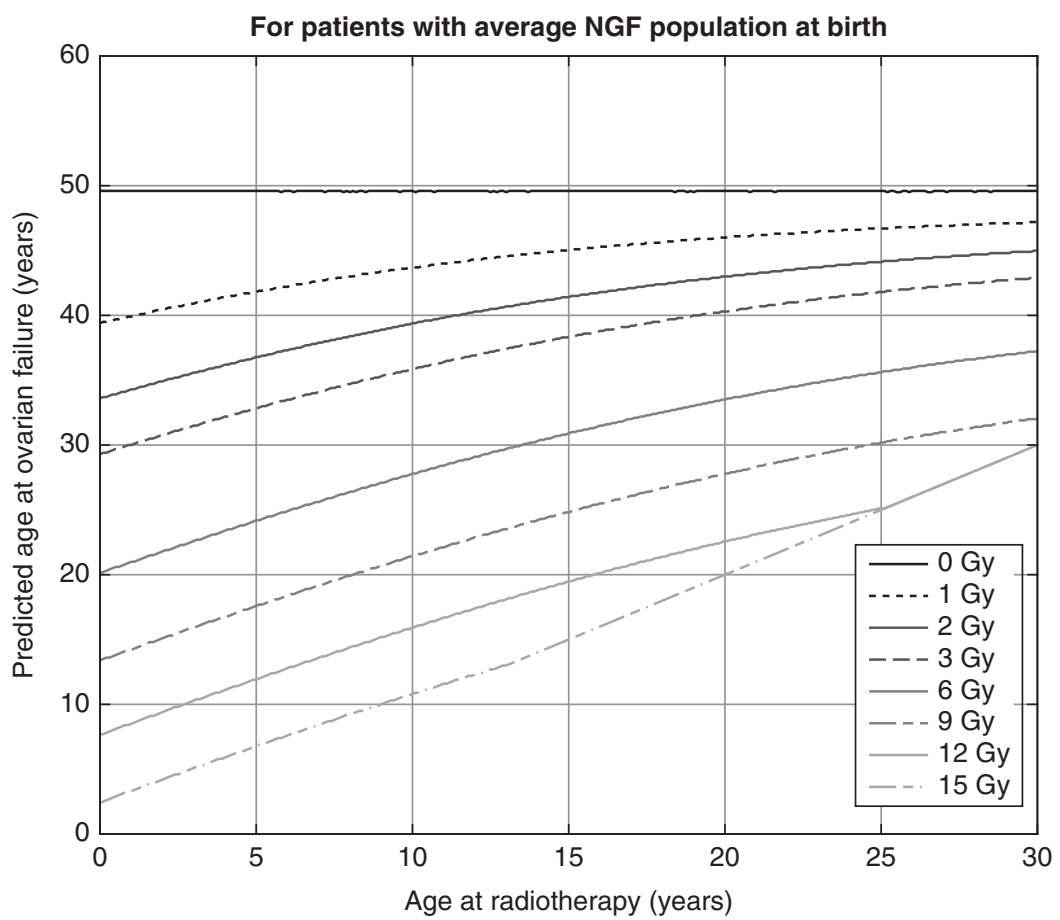

Figure 3.2 Predicted age at POI for known age and known dose to the ovary. A 5-year-old with average NGF population treated with 1 Gy has predicted POI at age 42, losing about 8 years of reproductive life span; the same child treated with 12 Gy has predicted $\mathrm{POI}$ at age 12, indicating consideration of the use of fertility preservation techniques. The predictions are modifications of existing predictions [25] adapted to use the Wallace-Kelsey model of NGF population in healthy females [9]

the surgical transposition of the ovaries outside the irradiation field before the initiation of pelvic radiation in adults with gynecological malignancies [24]. This approach may be considered for patients not planning to receive high-dose systemic chemotherapy. Surgery is effective at protecting the ovaries from direct irradiation damage, but fertility may be affected by scatter radiation, by damage to the ovarian vasculature during surgery, or by torsion of the transposed ovary. To avoid this, ovarian tissue cryopreservation may be considered at the same time as oophoropexy.

\section{Radiation and the Uterus}

The uterus is at significant risk of damage following abdominal irradiation, pelvic irradiation, or TBI in a dose- and age-dependent manner [32]. Uterine function may be impaired following radiation doses of 14-30 Gy as a consequence of disruption to uterine vasculature and musculature elasticity [23]. Even lower doses of irradiation, as in TBI, have been reported to cause impaired growth and blood flow [33]. The clinical consequences are increased risk of miscarriage and premature delivery [22]. A uterine contribution to an inability to conceive following radiotherapy is not clear but seems likely.

A small number of studies have been reported that attempted to improve uterine function in survivors of cancer with POI. In young adult women previously treated with TBI, physiological sex steroid replacement therapy improves uterine function (blood flow and endometrial thickness) and may potentially allow them to benefit from assisted reproductive technologies [33]. Larsen et al. studied uterine volume in 100 childhood cancer survivors and assessed uterine response to high-dose estrogen replacement therapy in three patients with ovarian failure and reduced uterine volume following abdominal and/or pelvic irradiation [34]. There was no significant difference in uterine volume, endometrial thickness, or uterine artery blood flow following sex steroid treatment, suggesting that higher doses of pelvic radiation cause greater damage than lower doses (as in TBI), and that this damage may be irreversible. While data are sparse for the childhood case, there is good evidence that adult women treated 


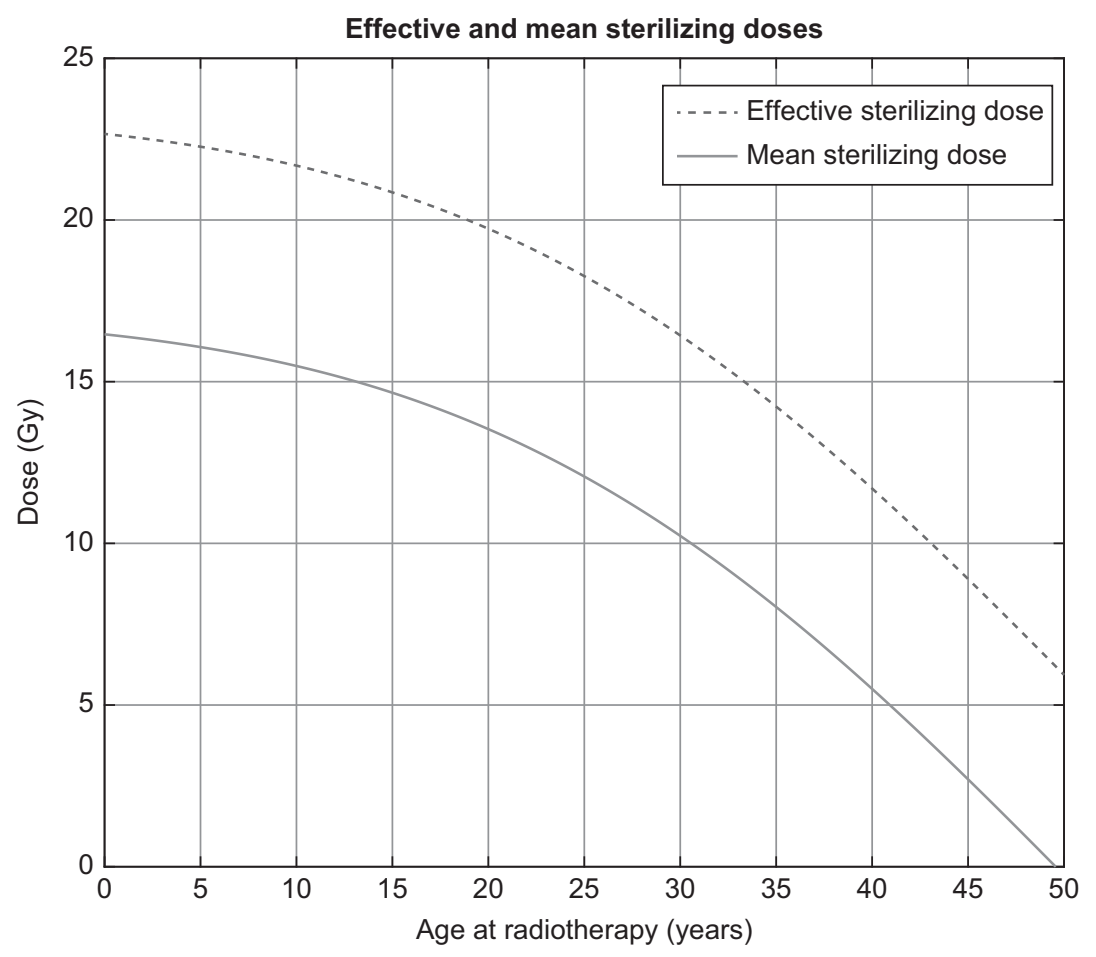

Figure 3.3 The mean and effective sterilizing doses of radiation to the human ovary. The blue line shows the radiation in Gy needed to sterilize $50 \%$ of subjects. The red line shows the radiation in Gy needed to sterilize $97.5 \%$ of subjects. The predictions are derived from the Wallace-Kelsey model of NGF population in healthy females [9], and the estimated radiosensitivity of the human NGFs [20]

with radiotherapy to the abdomen are at high risk of uterine dysfunction leading to miscarriage, premature delivery, low birth weight, and placental abnormalities [35]. There is no current evidence that the child uterus is inherently better protected from the effects of radiotherapy.

\section{Testicular Function}

In males, testicular damage can involve the somatic cells of the testis (Sertoli, peritubular myoid, and Leydig cells) or the germ cells. Spermatogonia are generally more radiosensitive and prone to undergo apoptosis than somatic cells [36]. Sertoli cells are responsible for nurturing developing germ cells, and Leydig cells produce testosterone. Recent data have revealed the essential contribution of peritubular myoid cells in mediating the effect of testosterone on spermatogenesis. Gonadal damage in males treated for cancer can result from either systemic chemotherapy or radiotherapy to a field that includes the testes. Cytotoxic treatment targets rapidly dividing cells, and it is therefore not surprising that spermatogenesis is impaired after treatment for cancer. The exact mechanism of this damage is uncertain, but it appears to be linked to depletion of the proliferating germ cell pool and associated stem spermatogonial cells. Although the prepubertal testis does not complete spermatogenesis and produce mature spermatozoa, cytotoxic treatment given to prepubertal boys may impair future fertility. Importantly, the prepubertal testis is susceptible to cytotoxic damage.

\section{Radiotherapy to the Testis}

In males, radiation doses as low as $0.1-1.2 \mathrm{~Gy}$ can impair spermatogenesis, with doses over $4 \mathrm{~Gy}$ causing permanent azoospermia. The somatic cells of the testis are more resistant than the germ cells, and Leydig cell dysfunction is not observed until 20 Gy in prepubertal boys and 30 Gy in sexually mature males [37].

Within the pediatric and adolescent age group, testicular damage occurs with direct irradiation to the testes, for example in the management of 
leukemia [38]. In patients with leukemic infiltration of their testes, radiation doses of $24 \mathrm{~Gy}$ are used, and this results in permanent azoospermia [39]. Total body irradiation applied as conditioning treatment before bone marrow transplantation (BMT) also irradiates the testes. However, the effects of this can be difficult to elucidate as it is usually given concurrently with alkylating agents, but doses of 9-10 Gy have produced gonadal dysfunction [40].

There have been many advances in technologies underpinning the delivery of radiotherapy, including intensity-modulated radiotherapy (IMRT), volumetric-modulated arc therapy (VMAT), and proton therapy (PT). There are case reports that suggest, for example, that IMRT can lead to a reduction in acute affects [41], and there is initial evidence that VMAT also reduces acute affects with PT reducing the risk of secondary malignancies in younger patients [42]. However, robust and largescale clinical trial evidence is lacking in this area, and hence accurate survey and meta-analysis studies are not yet possible. More data are needed before the precise effects of modern radiotherapy to the testis can be reliably estimated.

\section{Summary}

While many children and adults diagnosed with cancer can now realistically hope for long-term survival, they must often live with the consequences of their treatment. Infertility is one of the most devastating adverse effects of cancer treatment in this patient group. Radiotherapy can significantly impair future fertility, and treatments for certain cancers can be sterilizing [24]. Although predicting individual fertility following treatment is challenging due to the lack of biomarkers in children that indicate future fertility, we can both calculate sterilizing doses and predict age at POI on the assumption that the patient had close to average untreated fertility potential. Nevertheless, further epidemiological studies and investigation of markers indicating gonadal damage may be of use to our patients.

\section{References}

1. SEER. Surveillance, Epidemiology, and End Results (SEER) Program (www.seer.cancer.gov). SEER ${ }^{\star}$ Stat Database: Incidence, Survival \& Mortality, November 2017 ed. 2018.
2. Mertens AC, Yong J, Dietz AC, et al. Conditional survival in pediatric malignancies: analysis of data from the Childhood Cancer Survivor Study and the Surveillance, Epidemiology, and End Results Program. Cancer. 2015;121(7):1108-1117. DOI:10.1002/cncr.29170

3. Landier W, Armenian S, Bhatia S. Late effects of childhood cancer and its treatment. Pediatr Clin North Am, 2015;62(1):275-300. DOI:10.1016/j. pcl.2014.09.017

4. Anderson RA, Brewster DH, Wood R et al. The impact of cancer on subsequent chance of pregnancy: a population-based analysis. Hum Reprod, 2018;33(7):1281-1290. DOI:10.1093/ humrep/dey216

5. Wallace WH, Kelsey TW, Anderson RA. Fertility preservation in pre-pubertal girls with cancer: the role of ovarian tissue cryopreservation. Fertil Steril, 2016;105(1):6-12. DOI:10.1016/j. fertnstert.2015.11.041

6. Gerstl B, Sullivan E, Chong S et al. Reproductive outcomes after a childhood and adolescent young adult cancer diagnosis in female cancer survivors: a systematic review and meta-analysis. J Adolesc Young Adult Oncol, 2018. DOI:10.1089/ jayao.2018.0036

7. Depmann M, Faddy MJ, van der Schouw YT et al. The relationship between variation in size of the primordial follicle pool and age at natural menopause. J Clin Endocrinol Metab, 2015;100(6): E845-E851. DOI:10.1210/jc.2015-1298

8. Kelsey TW, Anderson RA, Wright P, Nelson SM, Wallace WH. Data-driven assessment of the human ovarian reserve. Mol Hum Reprod, 2012;18 (2):79-87. DOI:10.1093/molehr/gar059

9. Wallace WH, Kelsey TW. Human ovarian reserve from conception to the menopause. PLoS One, 2010;5(1):e8772. DOI:10.1371/journal. pone. 0008772

10. Johnson J, Canning J, Kaneko T, Pru JK, Tilly JL. Germline stem cells and follicular renewal in the postnatal mammalian ovary. Nature, 2004;428 (6979):145-150. DOI:10.1038/nature02316

11. Lee HJ, Selesniemi K, Niikura $Y$ et al. Bone marrow transplantation generates immature oocytes and rescues long-term fertility in a preclinical mouse model of chemotherapy-induced premature ovarian failure. J Clin Oncol, 2007;25(22):3198-3204. DOI:10.1200/JCO.2006.10.3028

12. Johnson J, Skaznik-Wikiel M, Lee HJ et al. Setting the record straight on data supporting postnatal oogenesis in female mammals. Cell Cycle, 2005;4 (11):1471-1477. DOI:10.4161/cc.4.11.2186 
13. Zou K, Yuan Z, Yang Z et al. Production of offspring from a germline stem cell line derived from neonatal ovaries. Nat Cell Biol, 2009;11 (5):631-636. DOI:10.1038/ncb1869

14. Hummitzsch K, Anderson RA, Wilhelm D et al. Stem cells, progenitor cells, and lineage decisions in the ovary. Endocr Rev, 2015;36(1):65-91. DOI:10.1210/er.2014-1079

15. McLaughlin M, Kelsey TW, Wallace WH, Anderson RA, Telfer EE. Non-growing follicle density is increased following adriamycin, bleomycin, vinblastine and dacarbazine (ABVD) chemotherapy in the adult human ovary. Hum Reprod, 2017;32(1):165-174. DOI:10.1093/ humrep/dew260

16. Jadoul P, Dolmans MM, Donnez J. Fertility preservation in girls during childhood: is it feasible, efficient and safe and to whom should it be proposed? Hum Reprod Update. 2010;16 (6):617-630. DOI:10.1093/humupd/dmq010

17. Gao W, Liang JX, Yan Q. Exposure to radiation therapy is associated with female reproductive health among childhood cancer survivors: a meta-analysis study. J Assist Reprod Genet, 2015;32 (8):1179-1186. DOI:10.1007/s10815-015-0490-6

18. Meirow D, Nugent $\mathrm{D}$. The effects of radiotherapy and chemotherapy on female reproduction. Hum Reprod Update, 2001;7(6):535-543.

19. Chow EJ, Stratton KL, Leisenring WM et al. Pregnancy after chemotherapy in male and female survivors of childhood cancer treated between 1970 and 1999: a report from the Childhood Cancer Survivor Study cohort. Lancet Oncol, 2016;17 (5):567-576. DOI:10.1016/S1470-2045(16)00086-3

20. Wallace WH, Thomson AB, Kelsey TW. The radiosensitivity of the human oocyte. Hum Reprod, 2003;18(1):117-121.

21. Salooja N, Szydlo RM, Socie G et al. Pregnancy outcomes after peripheral blood or bone marrow transplantation: a retrospective survey. Lancet, 2001;358(9278):271-276.

22. Sanders JE, Hawley J, Levy W et al. Pregnancies following high-dose cyclophosphamide with or without high-dose busulfan or total-body irradiation and bone marrow transplantation. Blood, 1996;87(7):3045-3052.

23. Wallace WH, Shalet SM, Crowne EC, MorrisJones PH, Gattamaneni HR. Ovarian failure following abdominal irradiation in childhood: natural history and prognosis. Clin Oncol ( $R$ Coll Radiol), 1989;1(2):75-79.

24. Anderson RA, Mitchell RT, Kelsey TW et al. Cancer treatment and gonadal function: experimental and established strategies for fertility preservation in children and young adults. Lancet
Diabetes Endocrinol, 2015;3(7):556-567.

DOI:10.1016/S2213-8587(15)00039-X

25. Wallace WH, Thomson AB, Saran F, Kelsey TW. Predicting age of ovarian failure after radiation to a field that includes the ovaries. Int J Radiat Oncol Biol Phys, 2005;62(3):738-744. DOI:10.1016/j. ijrobp.2004.11.038

26. Davies HA, Didcock E, Didi M et al. Growth, puberty and obesity after treatment for leukaemia. Acta Paediatr Suppl, 1995;411:45-50; discussion 1.

27. Bath LE, Anderson RA, Critchley HO, Kelnar CJ, Wallace WH. Hypothalamic-pituitary-ovarian dysfunction after prepubertal chemotherapy and cranial irradiation for acute leukaemia. Hum Reprod, 2001;16(9):1838-1844.

28. Constine LS, Woolf PD, Cann D et al. Hypothalamic-pituitary dysfunction after radiation for brain tumors. $N$ Engl J Med, 1993;328 (2):87-94. DOI:10.1056/NEJM199301143280203

29. Merchant TE, Rose SR, Bosley C et al. Growth hormone secretion after conformal radiation therapy in pediatric patients with localized brain tumors. J Clin Oncol, 2011;29(36):4776-4780. DOI:10.1200/JCO.2011.37.9453

30. Green DM, Nolan VG, Kawashima T et al. Decreased fertility among female childhood cancer survivors who received 22-27 Gy hypothalamic/pituitary irradiation: a report from the Childhood Cancer Survivor Study. Fertil Steril, 2011;95(6):1922-1927, 7 e1. DOI:10.1016/j. fertnstert.2011.02.002

31. Green DM, Kawashima T, Stovall M et al. Fertility of female survivors of childhood cancer: a report from the childhood cancer survivor study. J Clin Oncol, 2009;27(16):2677-2685. DOI:10.1200/ JCO.2008.20.1541

32. Marci R, Mallozzi M, Di Benedetto L et al. Radiations and female fertility. Reprod Biol Endocrinol, 2018;16(1):112. DOI:10.1186/s12958018-0432-0

33. Bath LE, Critchley HO, Chambers SE et al. Ovarian and uterine characteristics after total body irradiation in childhood and adolescence: response to sex steroid replacement. Br J Obstet Gynaecol, 1999;106(12):1265-1272.

34. Larsen EC, Schmiegelow K, Rechnitzer C et al. Radiotherapy at a young age reduces uterine volume of childhood cancer survivors. Acta Obstet Gynecol Scand, 2004;83(1):96-102.

35. Wo JY, Viswanathan AN. Impact of radiotherapy on fertility, pregnancy, and neonatal outcomes in female cancer patients. Int J Radiat Oncol Biol Phys, 2009;73(5):1304-1312. DOI:10.1016/j. ijrobp.2008.12.016 
36. Zheng Y, Lei Q, Jongejan A et al. The influence of retinoic acid-induced differentiation on the radiation response of male germline stem cells. DNA Repair (Amst), 2018;70:55-66. DOI:10.1016/ j.dnarep.2018.08.027

37. Shalet SM, Tsatsoulis A, Whitehead E, Read G. Vulnerability of the human Leydig cell to radiation damage is dependent upon age. J Endocrinol, 1989;120(1):161-165.

38. Castillo LA, Craft AW, Kernahan J, Evans RG, Aynsley-Green A. Gonadal function after 12-Gy testicular irradiation in childhood acute lymphoblastic leukaemia. Med Pediatr Oncol, 1990;18(3):185-189.

39. Grundy RG, Leiper AD, Stanhope R, Chessells JM. Survival and endocrine outcome after testicular relapse in acute lymphoblastic leukaemia. Arch Dis Child, 1997;76(3):190-196.

40. Leiper AD, Stanhope R, Lau T et al. The effect of total body irradiation and bone marrow transplantation during childhood and adolescence on growth and endocrine function. Br J Haematol, 1987;67(4):419-426.

41. Choi M, Hayes JP, Mehta MP et al. Using intensity-modulated radiotherapy to spare the kidney in a patient with seminoma and a solitary kidney: a case report. Tumori, 2013;99(2):e38-e42. DOI:10.1700/1283.14205

42. Jonska-Gmyrek J, Peczkowski P, Michalski W, et al. Radiotherapy in testicular germ cell tumours a literature review. Contemp Oncol (Pozn), 2017;21 (3):203-208. DOI:10.5114/wo.2017.69592 